\title{
Children in the Information Technology Design Process: A Review of Theories and their Applications
}

\author{
Valerie Nesset \& Andrew Large \\ Graduate School of Library \& Information Studies \\ McGill University \\ Montreal, Canada
}

\begin{abstract}
This article reviews the literature on the role that children can play in the design of information technology applications intended for young users themselves. It discusses several relevant design theories - User-Centered Design, Contextual Inquiry, Participatory Design, Cooperative Inquiry, Informant Design and Learner-Centered Design - looks at usability issues in relation to design and children, and presents a number of studies in which children have been actively involved in the design both of software and web portals. Designers are finding that children as well as adults can have a valuable and complementary role to play in the design process, although its precise nature is a matter of debate.
\end{abstract}

\section{Introduction}

As commercial software companies flourished in the late 1980s they realized that their designers required a better understanding of what users wanted and needed in terms of software design. Various design theories have evolved, based on the types of software and the target markets for which the software are developed. To address the subject of children and the design process, this article will first explore the different theories of design that have been adopted and/or adapted for work with children. It will look at usability as a crucial component of the design process, its definition, its role and how it is implemented in technology design. It will then discuss several studies in which children actively participated in all aspects of the design process.

\section{Design theories and children}

Designers are now adapting and adopting design theories suitable for the specific needs of children as designers of children's technologies. The design theories described below are limited to those that have been or could be adopted and/or adapted for children.

\section{User-centered Design}


The oldest and most conventional approach to design which includes users in the design process can be referred to as user-centered design. Although linked with all forms of design that include users, historically, user-centered design refers to a process undertaken once the technology has already been developed and released onto the market. As Head (1999, p. 158) states, "The traditional user-centered approach to designing an interface in the software industry is to assess an end-user's goals and to design within that context.” Scaife and Rogers (1999) note that this approach "has been typically to position users as a testing or evaluation service for designers to ensure those users' needs are met” (p. 28). Therefore, this approach focuses on the impact of the technology on users, enabling the development of future versions of the existing technology or the design of completely new technologies. Because the user, whether adult or child, is only involved after the technology has been designed, he or she has little or no control in the process. User-centered design is still employed as a tool to consider the future of new technologies and new educational uses of technology (Druin, 2002). Its underlying principle of user involvement has become a part of all the participatory design theories that have emerged since user-centered design was developed. The methods employed in user-centered design are many: observation, participant observation, system logs (these show patterns of interaction with different system tools), qualitative written surveys or interviews to determine likes, dislikes, difficulties, etc., quantitative surveys to collect statistics, pretests and posttests to determine the level of subject matter knowledge before and after using the technology, and analysis of the work done by the users with the technologies. In practice, several of these methods may be used simultaneously on the assumption that collectively a more reliable result is achieved. Comparative tests also are sometimes performed on users and non-users. In all cases the researchers look for changes in the use of the technology such as speed of performing a task, differences in content knowledge, and changes in activities over time. All research in user-centered design is focused on the impact of the technology on the child user (Druin, 2002).

One major drawback of user-centered design is that the users' involvement is limited. They cannot themselves initiate any changes but only reveal any design shortcomings. Another drawback directly associated with involving children in this approach is that the research methods such as task activities and questionnaires may be boring, and/or difficult for children to understand. An advantage, though, is that children can be incorporated into the research quite easily and in large numbers. Researchers may perform comprehensive studies with many children, producing remarkable results (e.g. Druin cites a 1991 Vanderbilt University study conducted with 1300 students which showed that technology helped children to learn). Through 
user-centered design, researchers can accomplish their work more quickly because they maintain control over the design process (Druin, 2002).

\section{Contextual Design}

Contextual Design (CD) is described by Beyer and Holtzblatt (1999, p.32) as "a state-ofthe-art approach to designing products directly from a designer's understanding of how the customer works". The aims of CD are to reveal the details and motivations of people's work, to make the customers and their work needs real to the designers, to use customer data as the basis of decision-making, and to create a shared understanding of the data by researchers and users. Its purpose is to reveal who the customers really are and how they work. CD calls for researchers to collect data in the users' own environment by observing them performing typical activities. The researchers usually record observational data by taking field notes and/or using audio-visual technologies. Even when conducting one-on-one interviews with the users at the workplace in order to develop a deeper understanding of the users' work, interaction between researchers and users is minimal since usually the researchers ask questions only for the purposes of clarification.

The researchers, to provide an understanding of the language and the structure of the work process, use a concept Beyer and Holtzblatt (1999, p. 35) term work modeling. It is valuable since "design teams seldom have the critical skill of seeing the structure of work done by others, looking past the surface detail to see the intents, strategies, and motivations that control how work is done". Five different work models are employed in CD. The flow model shows communication and coordination, the cultural model shows culture and policy, the sequence model shows the detailed steps to accomplish a task, the physical model represents the physical environment that supports the work, and the artifact model represents how artifacts are used and structured in the work. The advantages of constructing work models are that they are pictorial, easily and quickly viewed and understood and that they enable the designer to "take the next leap in understanding-from knowing the work of individual customers to understanding the fundamental structure of work for a whole customer population” (p. 35). It is this final benefit the ability to broaden understanding to a larger user base - that motivates researchers to adapt some parts of CD for use with children's technology designs. 
The next step in CD is consolidation. This involves making consolidation models and affinity diagrams of the data to identify common patterns and structure without losing the individual variations. Consolidation enables the designers to develop a focus and structure to design for the customer population's needs. Once this is accomplished the designers move on to the work redesign stage. In this phase the designers discuss the consolidated data and how technology can improve work practices. The design team uses storyboards to develop a vision of how the users will work with the new system. This keeps the focus on what matters to the customer-or in other words, the impact the technology will have on their work practices. The designers then develop a user environment design. This is a plan of the whole system capturing the flow, function, and structure of the entire system. This stage is intended to give the designers an overview of the technology in the hope that by doing so it will help them work as a team, preventing them from fixating on their own individual section of the design process.

The final phase of CD involves developing a low-tech prototype mock-up of the system and testing it with users. This allows for error detection and reparation before any coding has begun. As explained by Beyer and Holtzblatt (1999, pp. 40-41), "Paper prototypes support continuous iteration of the new system, keeping it faithful to the users' needs. Refining the design with users gives designers a customer-centered way to resolve disagreements and work out the next layer of requirements". They advocate paper prototypes because they are "always popular and always successful” as well as being quick to build and easy to run.

The use of low-tech paper prototypes, pictorial diagramming and concrete techniques lends itself to work with children. Although CD does not involve users in all aspects of the design process, it does provide a framework for the users' opinions and suggestions about the software to be heard and considered by the designers. CD's emphasis on a team approach and concrete methods of pictorial flowchart data analysis make it applicable and appropriate in a child-centered context.

\section{Participatory Design}

Participatory Design (PD) originated in the Scandinavian workplace and promotes workers' control over their work and their lives. Its premise is that users are the best qualified to determine how to improve their work and work life, and that their perceptions about technology are as important as technical specifications (Carmel, Whitaker, \& George, 1993). A highly iterative approach, goals and the strategies for accomplishing them are continually refined. PD looks to compromise rather than consensus as an end goal. It follows flexible practices and general 
guidelines; there is no standard set or ordering of practices, nor is there a set structure for the time frame of the project. As Fleming notes, "Through this approach, 'users move out of roles such as observer, approver 'knowledge repository'... and into roles such as peer co-designer, design owner, expertise contributor, and self-advocate” (Fleming in Bilal, 2002, p. 208). In PD, users move from extrinsic roles such as observer to intrinsic roles such as peer co-designer.

According to Carmel, Whitaker, and George (1993), there are two governing themes for the implementation of PD principles. The first is called mutual reciprocal learning. In this form of participatory design, users and designers teach each other about work practices and technical possibilities through joint experiences. The second theme is called design by doing. This makes use of interactive experimentation, modeling and testing support, hands-on design and learning by doing. It is a creative process using low-tech tools such as blackboards, index cards, and PostIt ${ }^{\mathrm{TM}}$ Notes. Along with some aspects of Contextual Design, design by doing is the form of PD that Druin makes use of in her design process, Cooperative Inquiry (see below).

PD makes use of two main techniques, modeling and metaphor-based design. Modeling consists of critique, fantasy or what-if scenarios, and implements these aspects through user action and To-do lists. Carmel, Whitaker, and George’s (1993, p. 44) description of metaphor-based design as a process that "generates metaphors for the current work situation and projects them into the future as a sort of conceptual prototyping process” depicts metaphor-based design as the more creative yet also the more practical of the two techniques in its use of metaphor and prototyping to represent the desired results.

Prototyping is integral to the PD methodology, since cooperative prototyping involves heightened user participation and "supports mutual learning by promoting cooperative communication" (Carmel, Whitaker, \& George, 1993, p. 45). Prototyping reinforces the iterative process of PD because designers collaborate as peers with the users in a mutual learning process (p. 46). Accompanying their article is a testimonial to PD's success by Joan Greenbaum (p. 47): "Since systems developers and people at workplaces do not experience the same things, this limits how well they can understand each other's experiences. One way of getting around this dilemma is to apply a PD approach to prototyping which emphasizes providing people with hands-on experience in a work-like setting." 
Although widely adopted, PD faces challenges from some software design professionals because of its reliance on design input from ordinary users. Muller and Kuhn (1993, p.26) address this issue when they ask, "Can software professionals recognize and affirm the validity of perspectives other than their own, and value the expertise that comes from experience, not just the knowledge that is attested by academic credentials”?

The principles of Participatory Design are the most suitable for design projects involving children. Children's school or home environments substitute for the workplace, their creativity and enthusiasm thrive within a flexible structure, and educational techniques have long stressed the benefits of mutual learning. The main difficulty of using PD techniques with children is similar to that raised in an adult context with Contextual Design, the benefits versus the drawbacks of using the opinions of the untrained user versus those of the design professional. A reluctance to involve children as active participants in PD lies in the disinclination of some in the professional design community to accept the notion that children are able to contribute to the process as true design partners.

\section{Cooperative Inquiry}

Developed by Druin and her colleagues at the University of Maryland, Cooperative Inquiry is a combination of techniques from different design methodologies that have proven useful when working with children. Based on the cooperative design practices of Scandinavian countries and the participatory design practices of the $\mathrm{U}$, the critical outcome of Cooperative Inquiry is design-centered learning. Cooperative Inquiry is grounded in HCI research and theories of cooperative design involving a multidisciplinary partnership with children, field research, and iterative low-tech and high-tech prototyping. A truly cooperative approach, Cooperative Inquiry treats children as full design partners-equals to the professional adult designers on the team. Professional designers and users (children) of the technology are partnered in intergenerational design teams with the understanding that full participation of users requires training and active cooperation. According to Druin (1999, p. 593), cooperative design methods informed Cooperative Inquiry because of their attempt "to capture the complexity and somewhat "messy" real-life world of the workplace. It was found that many times sequential tasks were not accomplished by one person, but many tasks were done in parallel and in collaboration with others. Interestingly enough, this description could also easily refer to the complexity and "messiness" of a child's world." 
Cooperative Inquiry comprises techniques from several different participative methodologies. The process of Cooperative Inquiry begins with techniques adopted and adapted from Contextual Inquiry (a part of Contextual Design) to accommodate work with children. These adaptations still exhibit the underlying principles of Contextual Inquiry, the most important of which is to observe users in their own environment. In order to best accommodate designing with children, Druin recommends adaptations to some of the Contextual Inquiry methods. In the capture of field data through observation, there should be one adult participant observer (similar to the role of a facilitator) and two note-takers so that the participant observer is free to interact with the children. This role is important because the participant observer is there to draw the children out and to provide gentle guidance, but only when needed; the observer is not to direct the children. Druin has found that when not told by an adult what to do, children are more exploratory than task-oriented-they do what they want to do instead of what adults expect of them. Therefore, it is important that the children lead the interaction, and not the adult researcher. The advantage to this approach is that the data collected is true to what the children really think, not what the children think the adults want from them. (Druin, 1999) The interactor must never take notes as children may find it distracting and/or intimidating. They may also see the interactor as an authority figure and as a result, may not give the same feedback they would give to a peer. The reason for two note-takers is that one can record the children's activities and the other can record their dialogue. Casual clothing should be worn by all of the researchers in order to avoid representing authority figures, and the interactor should be at the children's level in a physical sense. (e.g. The interacting adult should not be standing and watching the children if the children are doing something on the floor, but be down with them engaging in the activity.) The interactor needs to ask questions to draw out the children's thoughts and feelings, using informal language to express them. (Druin et. al., 1999) The members of the design team also make use of such Contextual Inquiry methods as brainstorming and interviewing in order to capture users' tasks, roles and design ideas (Druin, 2002).

These techniques from Contextual Inquiry facilitate observing what children do with existing technologies. Another technique that Druin borrows from Contextual Inquiry and adapts for Cooperative Inquiry is that of pictorial flowcharts. In Cooperative Inquiry, although the adults take notes (short text descriptions of conversation and activities), the children themselves combine "drawings with short amounts of text to create 'cartoon-like flow charts"” (Druin, 2002, p. 23). Druin uses this diagramming technique because she has found that children do not necessarily work in an orderly fashion. Often they may start multiple tasks without finishing any 
of them, and then decide to go back to one of the tasks later. Therefore, the researchers found it easier to depict this kind of activity by using diagrams of patterns of activity and the roles the children adopt rather than by the tasks they do. (Druin et al., 1999) The adults' and children's notes are compared for similar and new ideas, and an analysis of activity patterns of the children is made to identify roles that the children have taken throughout the session. (e.g. storyteller, collaborator, leader, etc.) (Druin, 2002).

Cooperative Inquiry also uses techniques from Participatory Design. In Participatory Design, the researchers listen to what the users have to say by direct collaboration in the development of lowtech prototypes. Unlike Contextual Inquiry, with its minimal interaction between researcher and user, Cooperative Inquiry involves more than observation. Low-tech prototypes are developed by the entire intergenerational team in order to support the brainstorming and idea generation stage of the design process. Low-tech prototyping, (e.g. paper-based prototypes) because of the nature of the activity and the materials used, also provides equal footing for children and adults. Lowtech prototyping is integral to Participatory Design, because the high-tech prototypes emerge from these initial low-tech ones (Carmel, Whitaker, \& George, 1993; Druin, 1999; Druin, 2002; Druin et al, 1999). In the Cooperative Inquiry approach, Druin combines different approaches to design in order to achieve the best results. As she states, "Low-tech prototyping is a much more effective design tool when done in concert with contextual inquiry. Based on design ideas that have emerged from contextual inquiry notes, prototyping can focus discussion and be a bridge for collaborative brainstorming activities” (Druin, 1999, p. 596).

As she did with the principles of Contextual Inquiry, Druin has adapted basic principles of Participatory Design to form part of the Cooperative Inquiry approach. Methods need to be adapted for use with an intergenerational team because the power dynamics are different and children must learn their new role as design partners. (They are used to the authority structure of teacher-student.) To accomplish this, she advises the team to invent something new (e.g., a new sandwich, or a new milk carton). Children and adults work together in small groups, brainstorming about what is wrong with the existing "technologies." Gradually the children become comfortable working as critics, designers and inventors. Druin considers children from the ages of 7 to 10 years old to be the ideal design partners because they are able to develop ideas from abstract concepts, but are still open to exploring new ideas. In order to put the children at ease, she insists on using more than one child and more than one adult on each design team in order to achieve an equitable balance of adults and children. Although she encourages the adults 
on the team to be playful, she reminds them to interact together as adults when appropriate. Druin provides diverse low-tech prototyping materials and encourages the team to use them as soon as possible, in different combinations and in non-traditional ways. She has found that the longer the team waits before using the prototyping tools, the simpler the final design is likely to be. Finally, she advocates a flexible goal or open-ended design problem to best make use of the Cooperative Inquiry methodology (Druin, et al., 1999).

Another technique that Druin has introduced into her Cooperative Inquiry approach is technology immersion, which involves observing what the children do when exposed to unlimited access to extraordinary amounts of technology. Used with the observational techniques of Contextual Inquiry and low-tech prototyping of Participatory Design, technology immersion is effective to identify roles and patterns that are not obvious in short Contextual Inquiry sessions. Druin finds technology immersion to be the most useful after some initial Contextual Inquiry and Participatory Design sessions have been undertaken (Druin, 1999; Druin, et al, 1999).

\section{Informant Design}

Developed by Scaife and his colleagues at Sussex University in England, Informant Design was introduced to address some of the perceived problems with user-centered and participatory design techniques when working with children. In conventional User-centered Design, users are involved only as evaluators or testers at the end of the design process and, therefore, their feedback is based on reaction rather than initiation. Furthermore, in User-centered Design it is up to the designers to translate and interpret the users' reactions and this can be an inaccurate practice. The perceived problem with Participatory Design is its promotion of equality for all team members. Scaife considers this approach to be effective for a team comprised of adult users who can view each other as peers, but infeasible when dealing with children. He does not believe that children have the time, knowledge or expertise to fully participate in the collaborative Participatory Design model (Scaife, Rogers, Aldrich, \& Davies, 1997).

For these reasons, Scaife chooses to take a position in between the User-centered and Participatory Design perspectives, and he calls his participants (children and teachers) "native informants" because they "are aware of aspects of learning/teaching practices that we are not and which we need to be told of ... So, by 'informant design' we mean an interplay between privileged observations from potential users and ourselves with another set of skills” (Scaife et al. 1997, p. 344). Rather than using the low-tech creative tools of PD, Scaife uses a blend of different 
low-tech and hi-tech methods, with careful consideration of how best to use low-tech materials when involving children. In this approach, "each informant provides different inputs to the design at various phases of the project using different methods.” As with PD and Cooperative Inquiry, iteration is crucial to this design approach.

The framework of Informant Design is structured in three phases with the first phase emphasizing learning goals and identifying strengths and weaknesses of current teaching practices within the domain. Teachers and children are involved separately as informants at this stage since their perspectives are so different. The designers examine the informants' input and then draft a list of problems. These problems are turned into functionality specifications in the second phase. In Phase 3 the specifications are used to design low-tech prototypes that are used by the child informants to suggest designs that are motivating for them. This input is used by design professionals to develop hi-tech prototypes. The child informants and teachers then test these prototypes and the design undergoes further iterations, if necessary. Although he finds it very useful, Scaife admits that there are problems with the approach because not all children are able or willing to be informants (Scaife et al., 1997).

Informant Design is an approach that attempts to maximize the input of the participants at various stages of the design process. Scaife believes that informants can help the researchers “...discover what we did not know rather than try to confirm what we thought we already knew. Such a philosophy is often overlooked by designers following a user-centered design approach in the excitement of demonstrating their own creative designs to users” (Scaife \& Rogers, 1999, p. 31). Scaife and his team advocate the use of a diversity of informants (e.g. teachers and children) to maximize the variety of suggestions. The designer tries to elicit suggestions from the children and then lets them know if it is possible to incorporate them into the working design. Scaife refers to earlier findings by Wong that rough sketches of interfaces are often much more appropriate prototypes for eliciting responses from users than more finished interfaces because they prevent users getting too fixated on low-level issues rather than asking more general questions. Moreover, if an informant is asked to evaluate a piece of software that is already designed by a user (child or adult) $\mathrm{s} /$ he is immediately limited to a lower level of detail in which to make suggestions (Scaife, et al, 1997; Scaife \& Rogers, 1999).

In Informant Design, each informant shapes the design at different points; at the beginning of the process it is to help "problematize the domain," in the middle to test and reflect upon the 
"cognitive and design assumptions, and at the end to evaluate the prototypes' 'real-world contexts'” (Scaife et al 1997, p. 350). Scaife and his colleagues consider informant design as an alternative to User-centered design or Participatory Design, and believe it to be the best method "for the design of interactive software for non-typical users or those who cannot be equal partners (e.g. children)” (Scaife et al, 1997, p. 346). Its basic assumption is that in the design process, children are most helpful at suggesting ideas for motivational and fun aspects of educational software.

\section{Learner-centered Design}

Soloway, Guzdial, and Hay (1994), expanding upon the idea that the long-term goal of computing is to make people smarter, decided that the HCI community needed to move from the traditional “user-centered” design to what they term Learner-centered Design. This approach assumes that everyone is a learner, whether a professional or a student. In fact, Soloway and his colleagues describe professionals as "students who happen to learn outside of a classroom" (p. 39). Therefore, the main focus of Learner-centered Design is to ensure that the interface design is adapted to the interests, knowledge and styles of the learners who use the software.

Soloway, Guzdial, and Hay (1994) believe in the educational philosophy of "learning by doing”. For them, "when learning is divorced from doing a meaningful task ... then learning becomes just another chore ...” (p. 40). The three issues addressed by user-centered design are tasks, (what does the software need to do?) tools, (what tools are provided to handle these tasks?) and interfaces (what is the interface to these tools?). The issues at the heart of learner-centered design are understanding, (how will the learner learn the practice?) motivation, (how can software motivate a learner?) diversity, (every learner is different-what kind of software can be developed that supports this?) and growth (the learner changes but the software does not).

To address these learning issues Soloway et al recommend using a "scaffolding technique" similar to that used in educational practices. In education, scaffolding is used to support learners while they are learning a new task. "Scaffolding, then, is provided to help a learner do a task that he or she can not [sic] do alone; as the learner develops the needed knowledge and skills, the scaffolding fades so that the learner is fully in control” (Soloway, Guzdial, \& Hay, 1994, p. 41). Soloway et al adapt the scaffolding technique for his “Task, Interface, Learner's needs, Tools” (or TILT) model of software design. In accordance with the constructivist theory of learning, Soloway insists that within the TILT model for software design there should be support for 
"constructing artifacts and conversing with others about those artifacts” (Soloway, Guzdial, \& Hay, 1994, p. 43). Since they view the construction of artifacts as a part of the design process, the TILT model contains scaffolding to support this premise: "Scaffolding is not an all-or-nothing deal. Good scaffolding is there when the student wants it, and is not there when the student wants to work independently” (Soloway, Guzdial, \& Hay, 1994, p. 46). In terms of implementing one design theory over another, as summed up by the authors, "if addressing the needs of users is the driver, then it is natural to focus on ease of use [user-centered design]; if addressing the needs of learners is the driver, then it is natural to focus on the development of understanding, performance and expertise [learner-centered design]” (Soloway, Guzdial \& Hay, 1994, p. 47). Of course, based on the tenants of Cooperative Inquiry, Druin would argue that no participatory design theory should be used to the exclusion of another, that different aspects of several appropriate design theories should be integrated into practice.

Kafai (1999) has adapted Soloway's approach for use with children by making them the actual software designers. To do this, one must be aware of children's preconceived notions about software so that one has an idea of the limitations and/or benefits that might entail. In order to achieve success, she believes it is also necessary that the child learners be involved in the evaluation and testing of the software. Her research showed that young student designers are similar to professional designers in their concern for their users. They were conscious of, and tried to address such issues as content and user motivation, but they did not always fully grasp how to address their users' other needs. Kafai is convinced, however, that children have the ability to become more than just informants in the design; rather, that they can become design process participants.

\section{Designing for children and children as designers}

Recently, researchers such as Druin et al (1996, 1997, 1999, 2002), Bilal (2000, 2002), Hanna et al (1997, 1999), Kafai (1999), and Large et al, (Large, Beheshti \& Raman, 2002; Large, Beheshti, Nesset, \& Bowler, in press, a; Large, Beheshti, Nesset, \& Bowler, in press, b) have advocated a more child-oriented approach to design. They argue that children have a lot to offer in the design process as a whole and that it is advisable to include them in it. Not all researchers, however, share their views. Nielsen (2002), for example, agrees about respecting the needs of children as expressed by children, in his case within the context of the Web. Most Web sites, he argues, are designed using, "pure folklore about how kids supposedly behave," and as a consequence, some 
of the children's sites are too complex and complicated. Children in fact seem to have the greatest success using websites intended for adults because these sites are simple and comply with Web design usability principles. From this it would seem that Nielsen is in agreement with Druin that it is desirable to involve children in the design process (or at the very least, act upon their suggestions regarding usability). Where Nielsen differs from Druin is in his opinion that children are incapable of overcoming many usability problems. From his research with children he found them impatient by nature, and thus, if the sites were too complex, the children simply left the website (Nielsen, 2000). He argues that this impatience precludes children from being able to critique sites for usability issues and subsequently, to make suggestions for improvement. Of course, this is much truer of the web environment than it would be, for example, in the case of software development. Druin herself does concede to at least one difficulty in the inclusion of children in the design process. She says that studies by Piaget in the early 1970's revealed that young children have a more difficult time verbalizing their thoughts, especially those dealing with abstract concepts and actions (Druin, 2002). Therefore, a lot of what they say "must be interpreted within the context of concrete experiences” (p. 2).

Harbeck and Sherman (1999), along with many developmentalists, agree that children can respond to stimuli in only a limited way and that because of this, exposure to stimuli should be controlled so as not to overload their receptive capabilities. They fear that "Virtual interactions could conceivably give children a distorted conception of the relation between simulated and actual representations of phenomena” (p. 40). A design project can be a very complicated, taxing task. To involve children in the process from beginning to end, as Druin does, could over-expose them to the stimuli to which Harbeck and Sherman refer. Conversely, however, involving the children would help them to overcome the problem of differentiating between simulations and actual phenomena.

Including children in the design process, then, has its advantages and disadvantages. Children can come up with ideas that adults might not think of (Druin, 1996; Scaife \& Rogers, 1999), but the downside is that they may want things included in the design that are impossible to realize. Yet constantly reminding children that certain things cannot be built may inhibit their creativity. Hanna, Risden and Alexander (1997) advise researchers to ground the children's expectations before they start the usability sessions by explaining exactly what the process will be. If not prepared in advance, many children expect to see a finished piece of software when they enter the testing area and may be disappointed when presented with a paper prototype. 
Rubin (1994) recommends using a multidisciplinary team approach. Why not adapt this approach to create a multigenerational, multidisciplinary team? As he states, "No longer can design be the province of one person or even of one specialty ... User-centered design requires a variety of skills, knowledge, and, most importantly, information about the intended user and usage” (p. 13). In the same way, for children's technologies, having children as part of the design team will provide that all-important information about the intended user and usage. In today's technologysavvy society, there is a growing recognition of the need to create technologies that will enable children to challenge themselves and to question the world around them. Druin (2002, p. 2) believes that involving children in the design process will address this issue. "We need to understand how we can create new technologies that offer children control of a world where they are so often not in control.”

Scaife and Rogers (1999) have found that “children can’t discuss learning goals that they have not yet reached themselves [and] interpreting children's dialogue is not as straightforward as may be assumed. In addition, there is the issue of overturning traditional power relations between adult and child ...” (p. 30). This issue of power relations is problematic. Scaife and his colleagues do not think that a complete overturn of power relations between adults and children can be achieved. As justification for using Informant Design over a completely participatory approach such as Cooperative Inquiry, Scaife asks if it is "possible for adults to treat children like themselves whilst at the same time not being patronizing? Conversely, can children make contributions about the content and the way they should be taught - something which adults have always been responsible for?” (Scaife et al, 1997, p. 343) Although Scaife et al recognize the value that children add to the process as informant designers, unlike Druin and her team (Druin, et al, 1997; Druin, et al, 1999; Druin, 2002), they cannot envisage children as completely equal design partners with adults.

\section{The role of children in the design process:}

Druin (2002) has defined four distinct roles that children can play in the design process. The role of user is the oldest of the four design roles and forms the basis of User-centered design theory. In this role children use existing technology and are observed by researchers in order to study the impact the technology has on the children. From this, the researchers can change and/or improve future technologies. 
The second role Druin defines as tester: children test prototypes of the technology before it is released onto the market. How the children interact with the prototypes affects how the development of future iterations of the technology is accomplished. The role of tester traces its historical roots to Seymour Papert's Logo research group at MIT during the 1980s and early 1990s where children identified problems, bugs, strengths and weaknesses in prototypes developed by adults. Although there is more control than in the user role, it is minimal since there is no guarantee that the testers' suggestions will be implemented. The role of tester became very popular in industry and academia during the 1990s, so popular, in fact, that it is unusual now if children do not test commercial technology products (Druin, 2002).

Druin (2002) believes that in the tester role there is less focus on educational directions; rather, the focus is on how well the technology meets the design goals. In the role of tester, the children's impact on the technology is fairly immediate in that a new feature suggested by the child tester or the discovery of a bug can be implemented or changed immediately. But compared to adults, the impact the children have on the technology is minimal because the children are not included in brainstorming or initial design phases. Druin (2002) hints that perhaps designers do not want to increase children's involvement beyond that of tester because children are honest and can be harsh in their assessments; this may be difficult for the developers to accept.

The third role is that of informant. It emerged in the mid-1990s when Scaife et al developed it as the basis of Informant Design. In this role, children participate in the design process at various stages in order to inform the design process (for example, they may be observed using existing technologies and then asked for input on design sketches and low-tech prototypes) but it is not a continuous involvement throughout the technology development. Data are collected by observation and interviews with the children early in the design process where the children's input is expressed by their words and/or actions, by the children's creation of low-tech prototypes, and by eliciting their design feedback. In the role of informant, the child can have an impact at the very outset on the direction of the development of the technologies. However, it is the adults on the team who choose which ideas will be used and when the children will be involved. Because it is more complex, the role of informant may take more time than the roles of user or tester. In the informant role, children feel empowered and challenged because the adults are interested in what they have to say (Druin, 2002). 
The final role as defined by Druin (2002) is design partner, which she uses in her Cooperative Inquiry approach to design. Here the children and adults are equal partners throughout the entire design process. In contrast to the roles of user, tester and informant, as design partner the impact roles are reversed; that is, children may have more impact on the technology design process than the impact of the technology has on the children. As design partners, the children embark upon a cooperative learning process that involves consensus participation.

As with any "real life" work situation, in the role of design partners the children and adults must negotiate team decisions. Problems can arise because not all professionals want to work with children as equal partners. Interestingly, Druin (2002, p. 4) does qualify the equality issue of this intergenerational partnership when she states, "As partners, children contribute to the process in ways that are appropriate for children and the process”. The question arises, who decides what is appropriate? How is this negotiated? One is reminded of Scaife's questions about how to deal with power dynamics and traditional adult-child interactions within the design team.

Notwithstanding these negatives, in the role of design partners children feel empowered and challenged. Rather than mere users of technology, they are helped to realize that they can really make a difference. For the adult researchers there are benefits as well; instant feedback is available when needed and this helps to immediately define the direction of the development process, saving time and money. However, the biggest potential impact the role of design partner has on the design of new technologies is the development of usable, innovative technologies that truly meet the needs of children.

\section{Usability}

Within the various design theories relating to software design, usability is a critical component. Since usability issues influence and form an integral part of the software design process, it is important to define what is meant by this term within the design context. "Usability" emerged from Human-Computer Interaction (HCI) studies, and is concerned with the development of systems that are user-centered (Head, 1997). Although there are many competing definitions, most experts would probably agree that usability describes the ability of the user to easily and intuitively understand and then navigate through the components of an interface. (Head, 1997; Nielsen, 2000; Rose, Shneiderman, \& Plaisant, 1995; Rubin, 1994) Since "users want cognitive cues that are visible and familiar and that help them navigate” (Head, 1997, p. 159), and "usability is rooted in cognitive science-the study of how people perceive and process 
information through learning, the use of memory and attention” (Head, 1999, p. 22), usability is concerned with the design of a product that meets users' needs. Hudson (2001, p.12) more broadly defines usability as "the experience that a user has while interacting with your site." She states that "one of the basic tenets of usability testing is that individuals experience sites differently according to their needs and abilities” (p. 13). Rubin refers to the work of Booth in his operational definition of usability. Booth regards usefulness, (the degree to which a product enables the user to achieve his/her goals and a measure of their motivation for using it) effectiveness, (the ease of use) learnability, (the user's ability to operate the system with some defined level of confidence after a predetermined amount and period of training and the ability to relearn the system after periods of inactivity) and attitude (likability or the user's perceptions, feelings and opinions of the product) as comprising the essence of usability (Booth as summarized by Rubin, 1994, p. 18-19). Microsoft Corporation regards usability as a practice in which "strategies for getting information about users into the development process in a timely way” are developed (Veldof, Prasse, \& Mills, 1999, p. 117).

Usability, then, can be understood as a concept rooted in the operational experience of the user. As such, it has guiding principles, attributes and practices that enable the designer to achieve a design that will meet the targeted users' needs. In an interview with Head (1999, p. 22), Nielsen identifies five attributes of a usable interface: (1) it is easy to learn, (2) efficient to use, (3) easy to remember, (4) causes few errors, (5) and is pleasant to use. This definition and its attributes of usability can be easily transferred to a children's context: the same rules apply, but they do need to be adapted and implemented for this specific target group.

Usability studies focus on how users think about, interact with, and retain information essential to the operation of the software. Most usability studies employ an iterative process whereby groups of users from the target market test the interfaces of software or Web sites. As part of the iteration, after the first testing session(s) the interface is redesigned, again tested by users, and then redesigned if necessary. This process continues until the desired design is achieved. If applied appropriately, usability studies can generate excellent data for analysis, enabling the designer to create a system embodying Nielsen's five attributes of usability. However, usability studies, like the technologies themselves, need to be designed with care. The usability of each new technology must be tested in a way most appropriate to its overall improvement. As Shneiderman (1992, p. 478) states, "Procedures vary greatly depending on the goals of the usability study, the number of expected users, the dangers of errors, and the level of investment." 
Usability studies have only become an integral part of the design of new technologies within the last decade or so. As Nielsen (2000, p. 388) affirms, "Usability used to be a suppressed and barely tolerated oddity in the computer industry. Computer companies have always refused to make usability the driving criterion in product development. Instead, features and performance were always the goals." If this was so, why has there been an overwhelming change in attitude towards usability studies in the past 15 or so years? One of the main reasons is profitability. Usability testing originally was performed on commercially released software in order to detect problems or areas that could be corrected in later versions. Soon designers realized that usability studies, if done as part of the design process, could detect potential problems before the technology was released onto the market. Since testers represent real users doing real tasks and provide a measure of how well a technology will work for its intended user base, not only does it ensure that the end product is satisfying and valued by the target population, but it saves the producing company a lot of money by making the improvements to the technology before it is released onto the market (Head, 1999).

Fichter (2001) recommends user-centered testing because the developers/designers are too close to the product to offer a truly objective evaluation of how well the technology works and how easy it is for an average person to use. It is better to have users say what is wrong, since designers can always provide a rationale for not making changes to their design. Rose, Shneiderman, and Plaisant (1995) consider usability studies as being crucial to technology development because the user's perception of a system is critical to its success. Scaife et al (1997 p. 343) take this one step further when they state, “The real issue would seem...to be not one of whether involving users is good or bad but rather how to more effectively engage them in the design process.”

\section{Usability studies and children}

Usability studies in the development of children's software are firmly rooted in the design process. What is different in the case of children's software, however, is that until very recently any usability research was carried out by adults rather than the target audience itself. As Hanna, Risden, Czerwinski, and Alexander (1999, p.4), researchers at Microsoft’s Hardware Ergonomics and Usability Department, comment: "Usability research with children has often been considered either too difficult to carry out with unruly subjects or not necessary for an audience that is satisfied with gratuitous animations and funny noises.” Even now, many software companies 
employ only adults in their usability testing. If children are involved, it is in the limited role of testers of the technologies at the very end of the design process. Their behavior while using the technologies to perform task-oriented activities is observed, recorded and analyzed by the adult design team and the team then makes any changes to the design.

Nielsen (2000) believes that children experience the same feelings of frustration, confusion, impatience and waning interest as do adults when confronted with usability problems. He states that poor technologies, whether aimed at children or adults, share common usability problems such as unclear location markers, inconsistent navigation options, non-standard interaction techniques, poor graphic and/or icon design for hypertext options, and complicated, complex wording. Although he considers his five usability attributes to be appropriate for both children and adults, Nielsen considers there are significant differences between designing for children and adults.

Hanna et al (1999) divide the design process into three stages: first, analyze the user's skills, expectations and knowledge; second, analyze the tasks that the product is to support, in other words, the goals of the product and the children; third, design the product in iterative phases based on the analysis of users and their tasks, test an idea, revise it according to feedback and then test the revised idea. They conducted expert reviews of the technologies, made site visits to children's homes (the child's equivalent of the adult workplace) in order to get information about the importance of features, (for example, the help feature was often shut off by users during gaming because they felt it interfered with the activity) distributed questionnaires that used pictorial representations (e.g., happy and sad faces) rather than Likert scales so that younger children would be able to understand and respond, initiated low-tech card-sorting tasks to check out hierarchies and categories, and conducted tests on low-tech prototypes (although the prototypes were developed by adults, not by children). They also used iterative laboratory tests (where the children test a feature of the software, and based on their abilities, it is then revised and retested if necessary) and longitudinal testing to evaluate the effectiveness of the educational content or techniques.

Druin's (1999, 2002) approach is different. In Cooperative Inquiry, she includes the children in all aspects of the design process, covering many more facets of the design process than simply the usability of the technology. She does, however, address usability issues as part of her overall design approach, using methods very similar to those of Hanna et al (1999). Druin, however, 
introduces the children to the design process before it has even begun. Her approach is much more informal than that of Hanna. Druin and her colleagues believe that observation and participation methodologies in use for usability studies do not address the difficulty in studying the constantly changing interaction between children and technology. They have found that when children are presented with the opportunity to use technology how they want to use it, they often do not have a defined task and instead engage in open-ended and exploratory activities (Druin, Bederson, Boltman, Miura, Knotts-Callahan, \& Platt, 1999).

\section{Children as designers in practice}

Reports in the literature of children as information technology designers are still very limited. Working with children as designers is a recent phenomenon and has not yet been widely accepted in the professional design community. Historically, there has been reluctance on the part of professional designers to regard children as equals or peers in a team setting. As Scaife believes and Druin admits, it is not every professional that can and/or wants to work in such a manner with children. Therefore, a method such as User-centered Design, and even the more participatory theories such as Contextual Design, Informant Design and Learner-centered Design, typically still use children only when their input is needed or wanted by adults. Thus adults remain very much in control of these design situations. However, there are several exceptions to this norm.

\section{KidPad: Cooperative Inquiry at work}

KidPad is the outcome of Druin's first efforts at employing Cooperative Inquiry as a design approach. Her belief that, "[while] children may not be programmers or engineers, they are experts in what they want and why they want it” (Druin, Stewart, Proft, Bederson, \& Hollan, 1997) propelled her to try to incorporate children's ideas into working software. Not only is the KidsTeam team intergenerational, but also, borrowing from the Contextual Design approach, it is interdisciplinary. Representatives from computer science, library studies, education and HCI took turns leading the activities, depending on what expertise was needed at the time. Druin advocates children's input before the technology design is even begun, and so in the KidPad project, through team collaboration, a knowledge base of information was developed before coding even began (Druin et al., 1997).

She found that collaboration with children is very different than with adults: "Children are experts at being kids; but exactly what that means is hard to say. They can't offer you a list of the five 
important things you must include in your technology. Often, children are not that self-aware or verbal about their needs. They must be given opportunities for communication and selfawareness, either through experience with technology or through participatory design exercises that ask them to see possibilities using low-tech prototyping tools” (Druin et al, 1997).

KidPad is the first result of Druin's intergenerational, interdisciplinary design team. Based on an existing storytelling software called Pad++, KidPad offers a zoom feature that supports and encourages the creation of non-linear stories. As Druin states, "It seemed to be a very natural way for children to tell their stories. They enjoyed the freedom of piecing together their thoughts and connecting them any which way they wanted to by zooming” (Druin et al., 1997). The design team, had it comprised only adults, with children acting in user or tester roles, probably would not have developed such a flexible, creative software. As the design process progressed, the designers picked up on many of the children's suggestions such as a toolbar of "local tools" including a crayon, an eraser, and an arrow with which they could select pictures from a picture scrapbook to drag onto the KidPad drawing surface. The children also suggested that the drawing tools offered by the software should be represented with icons instead of with text labels so that even very young children would be able to use them. Another feature recommended by the children is the "magic wand" which was developed in response to the children's frustration at getting lost when zooming. The Pad++ system provided similar functionality to the magic wand, but it was not intuitive for the children.

In the design of KidPad, the participation of the children (in terms of their suggestions, comments, etc.) allowed the adult designers to develop software that truly met the children's needs; and, as Nielsen would agree, this is the end goal of usability research. Another benefit that Druin and her colleagues discovered is that this software also supported collaboration between the children when they were writing and illustrating their stories on KidPad. As more of the children's ideas were incorporated into the KidPad software, their stories became more complex and richer in content and structure (Druin et al, 1997). These positive educational, social and learning outcomes reinforce the value of having children collaborate fully in the design process.

\section{A Children's Digital Library}

Druin and her colleagues, using the Cooperative Inquiry approach, are currently designing software suitable for a children's digital library. The intergenerational design team was split into 
three groups of two to three children, one teacher and one or two university researchers. Using low-tech prototyping materials, each group was asked to design a digital library of the future that would contain everything they wanted to know about animals. As with traditional participatory design approaches, the design process was iterative in nature. Once the brainstorming on the digital library of the future was completed, the team critiqued existing digital library systems containing animal content. The children then were given the opportunity to use the technology with the adults observing and taking field notes of what they were saying and doing. Following this, each child was asked to identify three things they liked about using the technology and three things they disliked. From analysis of these likes and dislikes, the researchers discovered that the children disliked the use of animated characters. This is indeed an interesting finding, in that it dispels a common misconception that all children love animation. The children also wanted a concrete purpose for performing a search and something done with the information once it is obtained. Once the adults understood the children's ideas, the observations of the technologies by the adults and the children were found to be very similar (Druin, Bederson, Hourcade, Sherman, Revelle, Platner, \& Weng, 2002).

A few more brainstorming sessions followed with periodic drawing by the children in their journals, another technique used in Cooperative Inquiry. This led to some critical ideas regarding how the query software should be structured (Druin et al, 2002). The resulting low-tech prototypes then were tried out in a school where the students' behavior while searching for information was observed. After more prototyping and informant testing, QueryKids was developed on the KidPad architecture. This system offers the search options of a virtual zoo with a map and images of animals that can be zoomed in on and then used as search criteria, a world area where the children can browse the animal database using geographical criteria, and a search area that provides the ability to "visually specify and manipulate queries" (Druin et al, 2002).

From this research, Druin surmises that if the children were restricted to the role of informant, they could only offer feedback and would not have the opportunity to elaborate or build upon ideas like they could as design partners. She also found that children want a concrete reason to look for information so that they can actually use the information they find. Druin is planning future research that will build upon the KidPad and QueryKids projects to include authoring tools in connection with a digital library. 
A children's digital library design project in England applied Druin's Cooperative Inquiry approach in an English Literature class of 23 children (11 year-olds) divided into teams of five or six. At the beginning of the project the groups browsed sample digital libraries and various children's websites. The children were then encouraged to make suggestions. Some of the suggestions were: that the digital library be divided into different areas; a study area for reading and/or browsing; a librarian area for asking questions; a games area; an online dictionary; and a traditional library area to search for books (Theng, Mohd-Nasir, Thimbleby, Buchanan, \& Jones, 2000). Rather than the design partners of Cooperative Inquiry, this study really used the children in the role of informants: although they were present from the beginning, their input was sporadic and there were few sessions involving the children. Nevertheless, the study's findings reinforce those of Druin, demonstrating that children want fun, easy-to-use interfaces and that any system that is designed should empower them as both authors and readers

\section{Web Portals}

Research into the design of Web portals (or search engines - in the literature, these two terms are often used interchangeably) by children, for children is still very much in its infancy despite research findings suggesting more effective and appropriate Web portals for children are required. As Bilal (2000) observes, because of perceived shortcomings by children of many of the existing children's search engines, many children prefer to use adult search engines. She is now herself investigating how children might design Web search engine interfaces (Bilal, 2002). Although she describes her approach as participatory design, with the participants as full design partners, unlike in Druin's methodology, no adults were involved in the design process and the 11 grade-seven children worked individually - there was no design team as such. In the first stage of the study Bilal had her participants each draw an interface on paper and on the verso list the purposes of the interfaces. After a short break the children used a commercial children's Web portal, Yahooligans! to search for information. They then discussed what they liked and disliked about it and noted the features they would want to add to their original drawings. Bilal interviewed each child individually to discover his/her rationale for adding the feature(s) to his/her drawing. She then repeated the same procedure with KidsClick, another children's Web portal. Bilal to date has only discussed her analysis of four of the eleven drawings. From these she discovered that "children are able to design screen layouts, dictate the features they need, and describe what these features should look like” (p. 213). She strongly recommends that designers of children's search engines not only ensure that their engines are "cool” but also that they offer high usability. 
Large, Beheshti, and Rahman (2002) focused on one aspect of a participatory design process in their utilization of a focus group approach to critique existing children's Web portals. From the outcomes of four focus groups they developed a list of design criteria for children's Web portals. The groups focused on the screen design and organization, navigability and usability of four different existing children's Web portals. Using a modified version of Contextual Inquiry, one researcher acted as a participant observer, interacting with the children, while the other researcher took notes. Rather than striving for consensus, in order to promote a "permissive environment" (Krueger, in Large, Beheshti, \& Rahman, 2002) the researchers encouraged the children to provide a variety of opinions and to express their own points of view. They found the focus group approach suitable for this type of research; although they recognize that peer pressure and the presence of more domineering children may play a part in group dynamics, they were satisfied that each child had his or her say. For the most part, their results are consistent with Bilal's findings concerning children's likes and dislikes about existing children's Web portals. They conclude that children are very capable of evaluating portals and making constructive suggestions as to how they might be improved to facilitate children's information seeking.

Continuing on from these focus groups, Large and his colleagues have been working with two intergenerational design teams to create Web portals for children. One team incorporated eight grade-six students and four adults, while a second team involved six grade-three students and four adults. In each team the children were involved from the outset in the design process leading to the successful development of two low-tech portal prototypes (Large, et al, in press a; Large, et $\mathrm{al}$, in press b). The researchers found that the children were able to comment cogently on Web portal design criteria, and generated ideas that the adults would not necessarily have developed by themselves. At the same time, the children were constrained by a lack of elementary knowledge concerning interface design principles, and, they say, it would be fallacious to underplay this fact. In answer to the question as to whether children and adults really can work as one, with no role differentiations, the answer was "to some extent". The children genuinely accepted the adults as a part of the team, and offered their ideas enthusiastically. At the same time, however, the latter found themselves leading and focusing discussions, and setting agendas. 


\section{Conclusion}

What can be concluded about these various design theories based upon the rather limited number of applications in the information technology field? It has become obvious that as children's likes, dislikes, wants and needs in relation to technology become more and more sophisticated, they must be involved in the design process in a meaningful way. Certainly, few if any current researchers would dispute the value of including children in at least some aspects of the design of children's technologies; the dispute lies in the methods for accomplishing this. The participatory design theories discussed in this article each have the potential to be adapted to include children as active participants. However, picking and choosing different aspects from these theories that can better facilitate the involvement of children will go a long way in achieving the usability goals set by experts such as Nielsen, Rubin, and Shneiderman as well as other goals significant to the design of information technologies. As Druin and Large have shown with their work with intergenerational design teams, reinforced by that of Hanna et al $(1997,1999)$ and Theng et al (2000) involving children as much as possible in the design process initiates and facilitates innovations and improvements to the final design that might not otherwise have been thought of by adult designers.

The research has shown, however, that there are limitations to involving children in all aspects of the design process. Children often have difficulty in expressing ideas (Large, et al, in press, a; Large, et al, in press, b) and learning goals they have not yet met, and as a result, may be unable to participate fully as design partners and can contribute only in an informant role (Scaife \& Rogers, 1999). In terms of working as an intergenerational design team, children are often very conscious of age differences, no matter how slight (Nielsen, 2002) and may need to be separated according to age (Hanna et al, 1999) in order to be able to participate effectively. Other difficulties in establishing intergenerational design teams are the dynamics of power relations between adult and child, and directly related to this, the fact that some professional designers may have difficulty accepting children as peers (Scaife et al 1997; Scaife \& Rogers, 1999). However, it should be noted that many of these drawbacks can be overcome as evidenced by the research conducted by Druin et al and Large et al, and that the notion of including children as full members of a design team merits further study. In order to better promote creativity, usability, and profitability, designers must move forward from the reactive process of including children towards the end of the design process in the limited roles of user and tester. Although not all children may be able to participate as full design partners, they can be involved as informants at salient points throughout the design process. And although participatory design techniques can 
often be expensive and time consuming when working with adults, and are likely to be more so with children, the advantages in terms of innovation and appropriateness of design can outweigh these negative factors. As has been established in this review, researchers have demonstrated the benefits of including children in the design process. Therefore, to modify the quote by Scaife et al (1997), in light of today's research into the development of children's technologies, it might now be said, "the real issue would seem to be not whether involving children is good or bad but rather how to more effectively engage them in the design process.”

\section{References}

Beyer, H. \& Holtzblatt, K. (1999, January). Contextual Design. ACM Interactions, 6, 32-42.

Bilal, D. (2002). Children design their interfaces for Web search engines: A participatory approach. Proceedings of the $30^{\text {th }}$ Annual Conference of the Canadian Association for Information Science. Howarth, L., Cronin C., \& Slawek, A., (eds.). 204-214.

Bilal, D. (2000). Children's use of the Yahooligans! Web search engine. I. Cognitive, physical and affective behaviors on fact-based search tasks. Journal of the American Society for Information Science. 51, 646-665.

Carmel, E., Whitaker, R., \& George, J. (1993). PD and Joint application design: A transatlantic comparison. Communications of the ACM,, 36(4), 40-48.

Druin,. (1996). A place called childhood. Interactions, 3, 17-22.

Druin, A. (1999). Cooperative inquiry: Developing new technologies for children with children. Proceedings of the SIGCHI conference on Human factors in computing systems, Williams, M., Altom, M. (chairpersons). New York, NY: ACM Press, 592-599.

Druin, A. (2002). The role of children in the design of new technology. Behaviour and Information Technology. 21, 1-25.

Druin, A., Bederson, B., Boltman, A., Miura, A., Knotts-Callahan, D., \& Platt, M. (1999). Children as our technology design partners. In A. Druin (Ed.), The design of children's technology. (pp. 51-72). San Francisco: Morgan Kaufmann Publishers.

Druin, A., Bederson, B., Hourcade, J.P., Sherman, L., Revelle, G., Platner, M., \& Weng, S. (2001). Designing a digital library for young children: An intergenerational partnership. Proceedings of the first ACM/IEEE-CS joint conference on Digital libraries. Fox E., Borman, C. (chairpersons). New York, NY: ACM Press, 398-405.

Druin, A., Stewart, J., Proft, D., Bederson, B., \& Hollan, J. (1997). KidPad: A design collaboration between children, technologists, and educators. Proceedings of the SIGCHI 
conference on Human factors in computing systems. Pemberton, S. (ed.). New York, NY: ACM Press, 463-470

Fichter, D. (2001, March/April). Testing the web site usability waters. Online. 25(2), 78-80.

Greenbaum, J. (1993). PD: A personal statement. Communications of the ACM. 36(4), 47.

Hanna, L., Risden, K., \& Alexander, D. (1997) Guidelines for usability testing with children. Interactions. 4(5), 9-14.

Hanna, L., Risden, K., Czerwinski, M., Alexander, D. (1999). The role of usability research in designing children's computer products. In A. Druin (Ed.), The design of children's technology. (pp. 4-26). San Francisco: Morgan Kaufmann Publishers.

Harbeck, J. \& Sherman, T. (1999, July-August). Seven principles for designing developmentally appropriate web sites for young children. Educational Technology, 39-44.

Head, A.. (1999, November/December). Web redemption and the promise of usability. Online, 23(6), 20-32.

Head, A. (1997). Web usability and essential interface design issues. Proceedings of the $18^{\text {th }}$ National Online Meeting. Williams, M., Hogan, T. (eds.). Medford, NJ: Information Today, 157-163.

Hudson, L. (2001, Summer) From theory to (virtual) reality. Library Journal-Net Connect, 12-15.

Kafai, Y. (1999). Children as designers, testers, and evaluators of educational software. In A. Druin (Ed.), The design of children's technology. (pp. 123-145). San Francisco: Morgan Kaufmann Publishers.

Large, A., Beheshti, J., Nesset, V., \& Bowler, L. Children as designers of Web portals. Proceedings of the ASIST Annual Meeting, Long Beach, CA. October 2003. Medford, NJ: Information Today. 40. In press.

Large, A., Beheshti, J., Nesset, V., \& Bowler, L. Children as Web portal designers: Where do we start? Proceedings of the $31^{\text {st }}$ Annual Conference of the Canadian Association for Information Science. Halifax, NS. May 30-June 1, 2003. In press.

Large, A., Beheshti, J., \& Rahman, T. (2002) Design criteria for children’s Web portals: The users speak out. Journal of the American Society for Information Science and Technology, 53(2), 79-94.

Muller, M. \& Kuhn, S. (1993). Participatory Design. Communications of the ACM, 36(6), 24-28.

Nielsen, J. (2000). Designing web usability. Indianapolis, IN: New Riders Publishing.

Nielsen, J. (2002, April) Kids' corner: Website usability for children. Alertbox, Retrieved 
September 8, 2002 from http://www.useit.com/alertbox/20020414.html.

Rose, A., Shneiderman, B., \& Plaisant, C. (1995). An applied ethnographic method for redesigning user interfaces. Conference proceedings on Designing interactive systems: Processes, practices, methods, \& techniques. Olson, G., Schuon, S. (eds.). New York, NY: ACM Press, 115-122.

Rubin, J. (1994). Handbook of usability testing: How to plan, design, and conduct effective tests. New York: Wiley.

Scaife, M. \& Rogers, Y. (1999). Kids as informants: Telling us what we didn’t know or confirming what we knew already. In A. Druin (Ed.), The design of children's technology. (pp. 27-50). San Francisco: Morgan Kaufmann Publishers.

Scaife, M., Rogers, Y., Aldrich, F., \& Davies, M. (1997). Designing for or designing with? Informant design for interactive learning environments. Proceedings of the SIGCHI conference on Human factors in computing systems. Pemberton, S. (ed.). New York, NY: ACM Press, 343-350.

Shneiderman, B. (1992). Designing the user interface: Strategies for effective human-computer interaction. $2^{\text {nd }}$ ed. Reading, MA: Addison-Wesley.

Soloway, E., Guzdial, M., \& Hay, K. (1994). Learner-centered design: The challenge for HCI in the $21^{\text {st }}$ century. Interactions, $1(2), 36-48$.

Theng, Y. L., Mohd-Nasir, N., Thimbleby, H., Buchanan, G., \& Jones, M. (2000) Designing a children's digital library with and for children. Proceedings of the fifth ACM conference on Digital libraries. Nürnberg, P., Hicks, D., Furuta, R. (chairpersons). New York, NY: ACM Press, 266-267.

Veldof, J.R., Prasse, M.J., \& Mills, V.A. (1999). Chauffeured by the user: usability in the electronic library. Journal of Library Administration, 26(3-4), 115-140. 